\title{
LINGUISTIC LANDSCAPE RESEARCH: SOME METHODOLOGICAL REMARKS
}

\author{
OLENA BUDARINA
}

\section{Introduction}

When we arrive in a new place, new country, we primarily pay attention to the different kinds of signs, which help us to orient, communicate and survive. Accessible to everyone, public signs, ads, billboards are often the first form of contact that we have with the language and script of the place. Nowadays the sings are such a taken-for-granted part of our everyday experience and, at the same time, an important source of information about sociolinguistic context and using of different languages.

In recent years, the linguistic content of publicly visible signage has caught the attention of researchers as a unique area of linguistics that deserves investigation. The presence of any language on the sign poses a number of questions: Who put it there? Why is it there? What communicative function does it serve? And finally, what does this say about multilingualism and language contact in a specific area?

\section{The study of the linguistic landscape}

Research on the language on signs dates back to the 1970s (Backhaus, 2007: 12; Spolsky, 2009: 26-27), but only since the publication of Landry and Bourhis's foundational article 'Linguistic landscape and ethnolinguistic vitality' in 1997, this sphere has become an important field of sociolinguistics and the object of interest of researchers from different countries. 
Studies of the linguistic landscape (LL) are concerned with a language in it written form, in the public sphere; language that is visible to all in a specified area (Gorter, 2006). According to Canadian researchers Rodrigue Landry and Richard Bourhis (1997: 25), it is 'the language of public road, signs, advertising boards, street names, place names, commercial shop signs, and public signs on government buildings combines to form the linguistic landscape of a given territory, region or urban agglomeration'. In other words, a linguistic landscape consists of all visual forms of language presented in the public space of a certain geographic area. This definition has been used in several other studies undertaken into linguistic landscapes (Backhaus, 2005; Ben-Rafael and Shohamy, 2006; Cenoz and Gorter, 2006; Huebner, 2006).

While the notion by Landry and Bourhis has become accepted by many researchers as a standard, Shohamy and Waksman (2009) took a step further and proposed an extended definition of LL, embracing all types of text, be it language or image, written or spoken, sounds or video; displayed (in certain time and space) inside buildings or outside, in the street or in the Internet. Backhaus (2006) argued that such expansion threatens to make LL intangible and too broad to study.

Another extension was offered by Gorter (2006), who suggested the term cityscape instead of linguistic landscape. His argument was that due to urbanization and globalization, most of LL studies are conducted in the cities, where different signs are concentrated among with multilingual population, language contacts, and language conflicts (Gorter, 2006). Nevertheless, researchers preferred to use the terms linguistic landscape or linguistic landscaping.

Geographically, the studies of LL cover a rather diverse area: cities in African, Asian, European, South- and Latin-American, and North-American countries. Some studies focused on one specific area, for example, Quito, Ecuador in Alm (2003) or the 'Golden Triangle' in Algarve, Portugal in Torkington (2008). Some researches engaged in comparative analyses of several areas within one country: Ben-Rafael, Shohamy, Amara, and Trumper-Hecht (2006) covered West and East Jerusalem, Tel-Aviv, Nazareth and several towns within the study of the Israel LL. Also, there were many comparative studies about areas in different countries - Friesland in the Netherlands and the Basque country in Spain (Cenoz and Gorter, 2006); Quebec in Canada and Tokyo in Japan (Backhaus, 2009), etc.

Interpretation of a linguistic landscape is a difficult task, and various approaches have been used to try and explain the patterns that have been observed. A particularly notable and significant aspect of linguistic landscapes is the sheer number of areas and matters where it can be applied to. It can be used to identify the linguistic boundaries of a certain area (Ben-Rafael and Shohamy, 2006); to assess the impact and penetration of multilingualism in a community 
(Huebner, 2006 and Cenoz and Gorter, 2006); to test sociolinguistic theories as Ben-Rafael and Shohamy (2006) have done. It can be used to analyse semiotics (Lou, 2007 and Stroud and Mpendukana, 2009), and they can be conducted as qualitative micro-level studies analysing metacultural patterns. (Coupland and Garrett, 2010).

Due to the interdisciplinary nature of LL studies and their still developing stage as a sub-field of sociolinguistics, different scholars apply various theoretical frameworks to their studies: from historical (Coulmas, 2009) to sociological (Ben-Rafael, Shohamy, et al., 2006), economic (Cenoz and Gorter, 2009), ecological (Hult, 2009), geo-semiotic, and sociolinguistic approaches (Spolsky, 2009). Most of the frameworks are not limited to linguistic analysis only, but use multiple modalities characteristic of LL and consistent thereof with a more inclusive definition.

As was noted above, the linguistic landscape refers to linguistic objects that mark the public space. Despite being a relatively new field, there have been a number of studies focusing on languages on signs around the world. The study of the linguistic landscape is particularly interesting in bilingual and multilingual contexts (Cenoz and Gorter, 2009: 68), because LL displays various instances of languages and scripts contact in the visual domain of language use, including official and private signs such as shop signs, advertising posters, billboards, etc.

\section{Methodology issues}

It is important to describe the methodology that was applied, to conduct meaningful comparisons of results from different scholars and to replicate linguistic landscape research at another time or in another sociolinguistic context.

The process of collecting and analysing of different kinds of signs seems to be very simple: photographing the sings and counting the number of each language variety occurrences. However, the studies of signs in a public space employ a variety of methodologies.

Quantitative vs. qualitative study. There are only quantitative or only qualitative LL studies, and those that combine the two. Some studies employ LL as a part of larger-scale studies of language usage. Quantitative studies involve choosing a site or sites for data collection and photographing and describing the signs, depending on what constitutes the unit of analysis for the study.

The signage analysis usually includes counting the signs and division of them into different categories (e.g., languages, types or themes). For quantitative analyses, taxonomies and classifications are very important, because they help to determine the patterns found in LL. The most commonly applied ones, have to do with the languages on the signs (mono-, bi-, or multilingual), types of signs 
based on their authorship (official, non-official), function and use (e.g., business names, advertisements, warnings, street names, etc.).

Qualitative studies focus on a selection of signs that are thoroughly described (spatial, linguistic, and content analysis), usually using more details and variables than signs classifications can provide. For instance, the colors used (Malinowski, 2009), the direction of the text (Scollon and Scollon, 2003), the meaning of the message (Curtin, 2009), the images and the impression of the place or sign (Shohamy and Waksman, 2009). Besides the sign description, the studies may include interviews with language users, sign-readers and signowners, historical development and observations of sites. The problem with qualitative-only study of LL is that there can be doubts about representativeness of signs chosen for analysis. Moreover, it is impossible to make conclusions about trends and dynamic of LL based on such data only.

Combining statistical data from quantitative analysis with more complex qualitative descriptions, can result in deeper analysis and produce more reliable interpretations.

Synchronic vs. diachronic study. The most LL studies were synchronic, attempting to capture the language situation at the moment of data collection. Backhaus (2007) in his review of LL studies found that synchronic studies of the same cities or countries conducted at different times could not provide accurate dynamic trends, because of the differences in geographic areas covered or sampled. A diachronic approach, on the other hand, shows the dynamic of LL within one area and allows to see and evaluate the changes in LL, as well as factors influencing those changes. In other words, diachronic studies are contextualized and comparative on their own. However, as Pavlenko (2009) has noted, 'rather few studies unfortunately take on a diachronic perspective'.

Spolsky and Cooper (1991) used a diachronic perspective in particular layering, when analyzing signs in the streets of Jerusalem and found how languages, their order, and translation in signage changed reflecting of that who had the power. Backhaus $(2005,2007)$ dedicated part of his research in Tokyo to how signs were changing with time by comparing older signs with newer ones and one of his findings was more adequate use of English on official signs at present, from the point of view of (native) English speakers.

Therefore, diachronic LL studies can confirm and elaborate the processes of political and socioeconomic changes, because language in public space can be used as an arena for power struggle and affirmation, linguistic and ethnolinguistic conflicts.

Studies of LL can be rather problematic, partially because LL is always multimodal, with language or text being only one of many modes present in public space and context (physical, social, political, economic) bearing much significance. Therefore, it is not surprising that many methodological and theoretical 
issues were raised, which could influence the quality of the studies and interstudy comparability. Backhaus (2007), Gorter (2006), Pavlenko (2009), and Spolsky (2009) are some of the scholars who summarized these issues. The main problems they mention are related to sampling (when an area of study cannot be covered through comprehensive data collection, sampling is used, which automatically brings the danger of overgeneralizing the findings (Backhaus, 2007; Gorter, 2006b; Pavlenko, 2009); the unit of analysis (the clear definition of the unit of analysis and which texts are to be counted) and categorizations of signs (combination of languages, authorship, code preference etc.).

LL research, though not fully developed in terms of a clearly defined notion of LL, its methodologies and theoretical frameworks, provides a large number of studies, diverse in geography, fields and methods of research. The interdisciplinary nature of public signage studies has proved to be useful in looking at what languages are used in certain areas, for what purposes, and how it compares with claimed ethnolinguistic diversity or monolingualism. The major issues in methodology have to do with decisions concerning where to collect data, what to consider as unit of analysis, and how to categorize data to get reliable and precise results.

\section{Linguistic landscape and multilingualism}

The linguistic landscape is deeply rooted in the language and cultural diversity of a city or area. Thus, the study of the LL can contribute to the understanding of language and cultural diversity as it reflects the population of the city, either the languages in use among the permanent inhabitants and immigrants or the way information is provided to visitors or tourists. In this case, the linguistic landscape can reflect the main features of a city's linguistic and cultural diversity. It is quite logical, that most research in this area has been conducted in multilingual societies and communities, including Israel (Ben-Rafael et al., 2006; Spolsky and Cooper, 1991), Quebec (Landry and Bourhis, 1997), Basque country (Cenoz and Gorter, 2006), and Wales (Coupland forthcoming). The representation of different languages in multilingual urban environments is a phenomenon that has emerged in linguistic landscape research in recent years (Ben-Rafael et al., 2006; Ben-Rafael, 2009; Cenoz and Gorter, 2006).

The majority of LL studies investigate the role of different languages in the city's graphic environment, seeking to understand the 'multiliterate ecology of cities' (Spolsky, 2009: 32). Sings are examined less in terms of their specific content, but with more regard to that languages are used and what this tells us about the relationship between different languages and their speakers. Cenoz and Gorter (2006) suggest that the linguistic landscape reflects not only to the status 
of different languages in society, but that it also acts as a force shaping how languages are being perceived and used by the population.

Research on the LL can give insights not so much into the languages used in a given territory, as into their status and the level of prestige they enjoy; in Laundry and Bourhis's (1997: 26) words: 'The predominance of one language on public signs relative to other languages can reflect the relative power and status of competing language group'. In case one or more of these languages enjoy some degree of official status, such research can also give insights into the actual languages policy in the region and their will to promote the recognised language/s, particularly in the case of official signs. In this respect, considering the case when one or more of these officially recognised languages are minority or regional languages, Laundry and Bourhis (1997: 29) wrote: 'Given that it is the dominant language group that can most effectively control the state apparatus regulating the language on public signs, one can consider the relative position of competing languages in the linguistic landscape as a measure of how the dominant group treats the linguistic minorities inhabiting the given territory'. In other words, LL is the source of information about the linguistic minority's status. Public texts indicate institutional recognition of the linguistic minority and can be used to measure a minority's social prominence (Landry and Bourhis 1997: 28). It is important to note that Landry and Bourhis's initial study was the first to come to the conclusion that linguistic landscapes can be used to mark the relative power of a specific language group.

\section{Further development and implementation of linguistic landscape studies}

Many LL studies have interdisciplinary character, connecting linguistics, semiotics, art, psychology, sociology, education, business, economics, statistics, geography, and politics. Due to the interdisciplinary nature of LL studies and still developing stage of LL as a sub-field of sociolinguistics, the interest of researchers of this discipline is growing.

With the globalization and the spread of English language all over the world, it is not surprising that there are many LL studies gauging the use of English in different places, including the contexts where English is neither an official nor a minority language.

Linguistic landscape research can help to describe present linguistic situation in particular place and would be a basis for a new language policy which would facilitate linguistic needs of all citizens in this area. Furthermore, this type of research could increase an efficiency of state national linguistic policy, facilitate a process of nation building. Linguistic landscape research may help us to identi- 
fy language trends, to trace the relation between minority languages and official language, and also to examine the role and positions of the English language as a language of globalization.

\section{Concluding remarks}

1. At the center of LL research are material forms of language visible in public spaces. Originated as a new approach to multilingualism, research in linguistic landscapes has typically focused on the varieties of language inscribed on the surface of a particular place. Furthermore, linguistic landscape research studies not only the signs, but investigates who initiates, creates, places, reads them as well.

2. The LL method investigates societal multilingualism by collecting and analyzing language on signs. Its advantages lie in the relatively easy way of obtaining a large amount of data. This data can be analysed from a quantitative point of view, to which a qualitative angle can be added by interviewing the persons responsible for or dealing with these signs. Also this data can be analysed using synchronic or diachronic approaches. Despite the apparent simplicity, studies of LL could be rather problematic.

3. The linguistic landscape studies are closely linked with multilingualism. The presence or absence of different languages in the linguistic landscape can provide us with an idea of their status or prestige, importance and power.

4. There are many various domains where LL studies can develop: multilingualism, language attitudes, education, literacies, language policy, language planning, psychology, studies of social (collective) identities, etc. However, one of the most prospective directions of LL studies nowadays is the linguistic landscape research in the context of minority languages (see e.g. Grześkowiak 2010), especially in the context of landscape research with reference to urban studies which have recently attained a highly developed status.

\section{References}

Alm, C.O. 2003. "English in the Ecuadorian commercial context". World Englishes 22. 143-158.

Backhaus, P. 2005. "Signs of multilingualism in Tokyo - a diachronic look at the linguistic landscape". International Journal of the Sociology of Language 175/176. 103-121.

Backhaus, P. 2006. "Multilingualism in Tokyo: a look into the linguistic landscape". In: Gorter, D. (Ed.). Linguistic landscape: a new approach to multilingualism. Clevedon: Multilingual Matters. 52-66.

Backhaus, P. 2007. Linguistic landscapes: a comparative study of urban multilingualism in Tokyo. Clevedon/Buffalo: Multilingual Matters.

Backhaus, P. 2009. "Rules and regulations in linguistic landscaping: a comparative perspective". In: Shohamy, E. and D. Gorter (Eds.). Linguistic landscape: expanding the scenery. London/ New York: Routledge. 157-172. 
Ben-Rafael, E., Shohamy, E., Amara, M.H. and N. Trumper-Hecht. 2006. "Linguistic landscape as symbolic construction of the public space: the case of Israel". In: Gorter, D. (Ed.). Linguistic landscape: new approach to multilingualism. Clevedon: Multilingual Matters. 7-30.

Ben-Rafael, E. 2009. "A sociological approach to the study of linguistic landscapes". In: Shohamy, E. and D. Gorter (Eds.). Linguistic landscape: expanding the scenery. London/New York: Routledge. 40-54.

Cenoz, J. and D. Gorter. 2006. "Linguistic landscape and minority languages". In: Gorter, D. (Ed.). Linguistic landscape: a new approach to multilingualism. Clevedon: Multilingual Matters. $67-80$.

Coulmas, F. 2009. "Linguistic landscaping and the seed of the public sphere". In: Shohamy, E. and D. Gorter (Eds.). Linguistic landscape: expanding the scenery. London/New York: Routledge. $13-24$.

Coupland, N. and P. Garrett. 2010. "Linguistic landscapes, discursive frames and metacultural performance: the case of Welsh Patagonia". International Journal of the Sociology of Language 205. 7-36.

Curtin, M. 2009. "Languages on display: indexical signs, identities and the linguistic landscape of Taipei". In: Shohamy, E. and D. Gorter (Eds.). Linguistic landscape: expanding the scenery. London/New York: Routledge. 221-237.

Gorter, D. (Ed.). 2006c. Linguistic landscape: a new approach to multilingualism. Clevedon: Multilingual Matters.

Grześkowiak, M. 2010. Trans-city or inter-city? The co-existence of majority and minority languages in the urban space: a comparative case study of London and Warsaw linguistic landscapes. Poznań: Katedra Ekokomunikacji UAM.

Huebner, T. 2006. "Bangkok's linguistic landscapes: environmental print, codemixing and lanugage change". In: Gorter, D. (Ed.). Linguistic landcape: a new approach to multilingualism. Clevedon: Multilingual Matters. 31-51.

Hult, F. M. 2009. "Language ecology and linguistic landscape analysis". In: E. Shohamy, E. and D. Gorter (Eds.). Linguistic landscape: expanding the scenery. London/New York: Routledge. 88-104.

Landry, R. and R.Y. Bourhis. 1997. "Linguistic landscape and ethnolinguistic vitality: an empirical study". Journal of Language and Social Psychology 16.1. 23-49.

Lou, J. 2007. "Revitalizing Chinatown into a heterotopia: a geosemiotic analysis of shop signs in Washington, D.C.'s Chinatown”. Space and Culture 10.2. 170-194.

Malinowski, D. 2009. "Authorship in the linguistic landscape: a multimodal-performative view". In: Shohamy, E. and D. Gorter (Eds.). Linguistic landscape: expanding the scenery. London/New York: Routledge. 107-125.

Pavlenko, A. 2009. "Language conflict in Post-Soviet linguistic landscapes". Journal of Slavic Linguistics 17.1-2. 247-274.

Scollon, R. and S.W. Scollon. 2003. Discourses in place: language in the material world. London/New York: Routledge.

Shohamy, E. and S. Waksman. 2009. "Linguistic landscape as an ecological arena: modalities, meanings, negotiations, education". In: Shohamy, E. and D. Gorter (Eds.). Linguistic landscape: expanding the scenery. London/New York: Routledge. 313-331.

Spolsky, B. and R.L. Cooper. 1991. The languages of Jerusalem. Oxford/New York: Oxford University Press.

Spolsky, B. 2009. "Progelomena to a sociolinguistic theory of public signage". In: Shohamy, E. and D. Gorter (Eds.). Linguistic landcape: expanding the scenery. London/New York: Routledge. 25-39.

Torkington, K. 2008. "Exploring the linguistic landscape: the case of the 'Golden Triangle' in the Algarve, Portugal". Paper presented at the Lancaster University Postgraduate Conference in Linguistics and Language Teaching. Retrieved December 20, 2009 from http://www.ling. lancs.ac.uk/pgconference/v03.htm 